\title{
Teaching and Assessing High-order Skills by Design and Technology Teachers in Botswana
}

\author{
Ngakaemang, K. M. \\ Department of Educational Foundations \\ University of Botswana \\ Nenty, H. J. \\ Department of Educational Foundations \\ University of Botswana
}

\begin{abstract}
Poor students' performance in design and technology (D\&T), especially at questions that call on high-order cognitive skills at national examinations, is symptomatic of teaching and assessment problems at classroom level. While it is accepted that this problem of poor performance could be multi-faceted, it is believed that a lasting solution can be found through the application of Bloom's taxonomy of cognitive skills while preparing for and teaching in the classroom. Using a methodology orientated towards the quantitative paradigm within the post positivist philosophy and a validated questionnaire instrument, data was collected from 45 D\&T teachers sampled purposively from 16 junior secondary schools in south eastern region of Botswana. Data analysis was done to test two related hypotheses and it was found that while D\&T teachers teach to develop each of Bloom's cognitive skill at a significant level, except generally for low-order skills, they were not able to do this when it came to assessment. These findings were discussed and relevant recommendations were drawn.
\end{abstract}

Key words: Design and technology; Bloom's taxonomy of cognitive skills; teaching and assessment; higher-order skills; Botswana Examination Council.

\section{INTRODUCTION OF THE PROBLEM}

According to Kerka [1] "higher order thinking skills are essential and must be taught. Recent findings of cognitive research provide a better understanding of how people learn and how they solve problems, from which new teaching strategies are emerging" (p. 23). But in Botswana, teachers do not do a good job at teaching for the development and assessing higherorder cognitive skills in D\&T among students in Botswana junior secondary school in South East region. This has negatively affected the students' proficiency and performance in this subject. According to deputy permanent secretary in the Ministry of Education and Skills Development (Kewagamang, [2]):

For a long time design and technology has not been doing well. For the past five years, the subject's national average pass rate was 23.5 per cent, 26.8 per cent, 11.4 per cent, 26.8 per cent, 10.1 per cent 14.1 per cent respectively, at junior secondary school level, while at senior secondary level it was 33.22 per cent, 26.4 per cent, 28.8 per cent, 23.58 per cent and 23.39 per cent respectively (p. 26).

Furthermore, according to Molwane [3] head of the Department of Industrial Design and Technology, University of Botswana, the declining rate of students' performance in design and technology in 2012 where the national average rate was 11 per cent at Junior Certificate and 20 per cent at BGCSE also indicate a crisis. What students are learning does not relate to what 
they are supposed to be learning. He advised D\&T teachers to give students design tasks in order to develop and gauge their level of understanding of the subject, rather than giving a huge amount of work on multiple choice questions.

When officiating at the Central Region Design and Technology Exhibition (CEREDTEX, VensonMoitoi [4], said Botswana is faced with the greatest challenge of having an adequate technology literate workforce. She said her ministry is keen to see the development of young people as future engineers and technologists. She believed that design and technology is one subject that could make a significant contribution to this country because it aims at producing multi-skilled, versatile, and adaptable youngsters who are capable of making a major contribution to the development of this country.

The Ministry of Education and Skills Development through regional operations have tried to improve both teaching and assessment in schools by establishing clusters of schools. The duties of these clusters are to do common scheming and tests. However, the researcher observed that clusters are having short-coming or impeding factors which include: (a) tests or assessments are poor and invalid because they do not assess higher-order cognitive skills (b) the clusters do not empower teachers on how to teach or deliver the content of design and technology especially on problem solving skills necessary in this subject. For instance, teachers are still teaching design and technology as a subject which does not need students to think. Finally, dimension three or Paper 3 is not assessed during formative assessments such as midyear and end of year examinations.

\section{Background of the study}

According to Botswana Examination Council [5] the design and technology assessment procedures are designed to provide a framework for assessing candidates who have completed a three-year course based on the Junior Secondary Design and Technology Teaching Syllabus. The D\&T examination aims to assess the knowledge and skills acquired through instruction in the content prescribed for the programme. The assessment designed in a way that encourages candidates to show what they know and can do, and their level of understanding. Furthermore, the procedures offer a general framework for syllabus content representation in examination papers and assure comparability of sampled content from year to year. The outcome of instruction in the content prescribed by the design and technology teaching syllabus will be assessed through three papers (p. 6).

D\&T has challenges or problems at the school levels resulting in its declining performance, whereas, other practical subjects like Art are doing better in terms of performance. For instance, according to 2012 result summary by BEC, the national average performance of art design is 53.3 per cent while design and technology is 11.4 per cent.

Table 1 shows the performance in D\&T from 2008 up to 2014. The grades A, B and C are regarded as quality pass in all subjects of junior certificate including D\&T. According to Table 1 , design and technology in the national examination is doing poorly in terms of students' performance. It is evident from Table 1 that between 2008 and 2014, the average pass rate of this subject is below 30 per cent. This region covers 21 junior secondary schools. The quality pass rate of this subject in 20 junior secondary schools are below 50 per cent but only 1 junior school has quality pass rate of 78 per cent. Therefore, the rest are below and this is clear indication of the problem in design and technology (D\&T). 
Table 1

National Junior Certificate D\&T Quality Pass 2008-2014 (A-C)

\begin{tabular}{|c|c|}
\hline Year & Pass rate of JCE (\%) \\
\hline 2008 & 24.0 \\
\hline 2009 & 25.5 \\
\hline 2010 & 23.5 \\
\hline 2011 & 26.8 \\
\hline 2012 & 11.4 \\
\hline 2013 & 10.1 \\
\hline 2014 & 14.1 \\
\hline
\end{tabular}

(Source: Botswana Examination Council, 2009 - 2014)

The performance of D\&T students in school based assessment cannot predict the students' performance in the national examination. For instance, some students do well in school based assessments but they do poor in the national examination. According to assessment procedures of Botswana Examination Council [5] the outcome of instruction in the content prescribed by the design and technology teaching syllabus will be assessed or tested through three papers of various by rate. For example, Paper 1 consists of multiple-choice items and is weighted 20 per cent. Paper 2 has two sections and is rated 40 per cent. The last one is Paper 3 commonly known as project. It has both portfolio work and product. It is rated 40 per cent.

\section{Theoretical and Conceptual Foundations}

This research is informed by Bloom taxonomy of human cognitive behavior (Bloom [6] which, as identified by Nenty [7], supports the assessment of design and technology from low order skills up to higher-order skills. The first level is memory which aims at developing and assessing the capability to recall such as definitions of terms of both resistance materials, and their identification. Therefore, stage one is applicable to both teaching and assessment of design and technology. In this subject, students are assessed to define technical terms and safety concepts. The second stage which is applicable to teaching and assessment of design and technology is comprehension. The objective of this stage or phase is to measure or gauge capability or competency of the students to make meaning out of what is in the memory. Some of the action verbs for the second level of Bloom taxonomy are comparing, contrasting, converting, determining, illustrating and others.

Design and technology students are gauged on this stage to express their design knowledge. However, at these two stages only lower order skills are taught and assessed in this subject. The third level which is also applicable to both teaching and assessing design and technology is application. The purpose of this stage is to gauge the capacity of the students to apply what is known in a practical situation. For instance, the students have to identify situational problems within their community and apply design skills or knowledge to solve the problem. The students will state, describe and illustrate the problem. This stage is relevant to both teaching and assessment in design and technology. The fourth stage of Bloom taxonomy is analysis and is relevant to both teaching and assessment in design and technology at junior secondary levels. This stage falls under higher order cognitive skills in both teaching and assessment in design and technology. At this stage, students are gauged on how well they can breakdown information or words of arts, manual and power machines. For instance, design process in paper three commonly known as course work the students are expected to analyze existing products or ideas relevant to their problem situation. They identify materials used on those 
products, strengths and the weaknesses of those existing products. The intention of this stage is to prepare learners to be able to come up with the right products to solve identified problem.

The fifth stage is synthesis and it is applicable in both teaching and assessment of higher-order cognitive skills in design and technology. The objective of this step is to develop and assess the ability or capacity to be innovative, in other words, creative. In synthesis the students have to apply their innovative skills or capability to come up with something new (novel) or new products. The product has to work better than the previous one in order to solve the problem. On this stage the learners have to be innovative and creative. The final stage of Bloom taxonomy is evaluation. It is relevant and applicable to the development and assessment of teaching and assessment of higher-order cognitive skills in design and technology. The objective of this stage is to measure or gauge capacity to use intelligence, to criticize and appreciate. For instance, after designing and making a product the students have to pass judgment to that product. In this stage learners will identify both strengths and weaknesses of the product.

Some students in this stage have a tendency of hiding weaknesses but it is punishable by marking key of design and technology. All six levels of Bloom taxonomy are relevant to both teaching and assessing in design and technology. Therefore, this research will be informed by all six (6) levels of cognitive domain of Bloom taxonomy. Gagne, Briggs, \& Wager [8] advocated that learning tasks for academic skills can be controlled in a hierarchy according to complexity: stimulus recognition, response generation, procedure following, use of terminology, discriminations, concept formation, rule application, and problem solving. For instance, in design and technology 'problem solving' can be seen in both dimension two and three (Papers 2 \&3). The students are expected to use their brains or cognitive skills to identify problem and use their design skills to arrest that problem. The key significance of the hierarchy is to identify prerequisites that should be finished to facilitate learning at each level. Fundamentals are identified by doing a task analysis of learning task

The study is informed by two (2) conceptual frameworks, the first one (1) is design thinking or design theory and the second framework (2) is Blooms' Digital Taxonomy. Scott-Webber and Corcorran [9] described design thinking as "proven and repeatable problem solving protocol that any business or profession can employ to achieve extraordinary results (p. 26)". Therefore, this model is applicable to both teaching and assessment of higher-order cognitive skills in D\&T because it involves people, space, artifacts, materials and aesthetic experiences following the process of transformation from a design concept to a tangible product.

\section{Statement of the Problem}

Most of D\&T teachers at Botswana junior certificate level teach to develop and assess mostly low order task or low order cognitive skills in design and technology and ignore higher-order cognitive skills. The junior certificate examinations levels in design and technology require students to demonstrate higher order cognitive skills in the subject but the performance of the students over the years does not portray this due to D\&T teachers inability to teach (instruct) and assess these skills. The students' performance in design technology is poor and the public is always of the idea that they go into the examination without knowing how to handle items in D\&T. The students are not learning what they are supposed to be learning in the subject. The quality of school based assessment D\&T is lowering the students' enjoyment in the subject. 


\section{Purpose of the study}

The purpose of the research study is to find out how higher order cognitive skills are being taught and assessed in design and technology in Botswana junior secondary schools in the South East region. The research proposes to gauge or measure both teaching and assessment in D\&T at Botswana junior secondary school levels especially of higher-order cognitive domain. The results of this study will be used to advise the stakeholders such as Department of Secondary in the Ministry of Education and Skills Development to address the challenges identified by the study. The research study also aims at improving the students' performance in D\&T.

\section{Objectives of the study}

To find out the extent to which D\&T teachers in Botswana junior secondary schools teach for the development of skills in all Bloom's cognitive dimensions in the subject.

- To find out the extent to which D\&T teachers in Botswana Junior Secondary Schools asses students' skills in all Bloom's cognitive dimensions.

\section{Following from these, the study is designed to find answers to the following questions:}

- To what extent do D\&T teachers in Botswana junior secondary schools teach for the development of skills in all of Bloom's cognitive dimensions in the subject?

- To what extent do D\&T teachers asses Bloom's cognitive skills?

\section{RESEARCH HYPOTHESES}

1. To a significant level, D\&T teachers in Botswana junior secondary schools in South East region teach to develop all skills at each level of Bloom's taxonomy.

2. To a significant level, D\&T teachers in Botswana junior secondary schools in South East region assess to develop all skills at each level of Bloom's taxonomy.

\section{REVIEW OF RELATED LITERATURE \\ Teaching and Assessment of Higher-order Skills}

According to Masek and Yamin [10] critical thinking has an important repercussion for relocate of acquaintance and purpose of problem solving skills to narrative situations. In this ability, several reward for students education are claimed to increase critical thinking ability. The author continue to add that common teaching critical thinking is the same essential as for an individual is being taught. On the other hand, spotted that instructing through critical thinking is about teaching students to correctly use concepts, principles, and measures, so that they are competent of producing successful outcomes and critical judgments.

Moalosi [11] has raised concern on the declining performance of students in junior secondary schools. The 2009 junior certificate results are a testimony to this concern. This research study investigates the response of Botswana junior secondary school teachers on three subscales: the Teacher Sense of Self Efficacy scale (TSES), efficacy in student engagement, instructional strategies and classroom management. The findings of this study suggest that teachers do not fully engage students in learning activities. Based on this study, decline in students' performance can be linked to teachers' failure to fully engage students in learning. Recommendations on how to engage students in learning were offered. The findings of this study are pointing towards weaknesses that exist within teaching. For instance, it was pointed out that if the students are not well engaged in their learning they become passive or inactive. They cannot think divergently because they always receive information from their teachers instead of searching information for themselves. The instructional strategy is very vital in teaching of higher-order cognitive skills. The above study links poor teaching strategy with declining students' performance in Botswana junior secondary school level. 
D\&T is a very complex subject with many entities and it is still evolving. It is very dynamic and encompasses complex concepts of problem solving or designing solutions for problems, innovation, imagination and flexibility. D\&T contributes to the school curriculum by preparing students to cope in a rapidly changing technological world. It enables them to understand how to think and intervene creatively to improve that world, combining their knowledge with their understanding of aesthetics and function. The students learn to become autonomous and creative problem solvers both individual and working with others. Assessing design and technology however, is not an easy task. Assessment in technology education has evolved but it is still very contentious. The three year junior certificate programme in Botswana has implications for assessment; assessment at school level and assessment at national level. The ethnographic research methods used by the author observed various loop holes in the current practices of assessment in the junior certificate programme. The end of Year 3 is a terminal point where students are examined externally. In practice the situation is different, there are regular summative assessment activities undertaken in schools by D\&T teachers. The school summative assessment is used to determine the best students who are given prizes at end of the term and during open day. At school assessment level the project work is not used to gauge the students' performance. Classroom evaluation practices generally encourage superficial and rote learning, concentrating on recall of isolated details, usually items of knowledge which pupils soon forget. Teachers do not generally review the assessment questions that they use and do not discuss them critically with peers, so there is little reflection on what is being assessed. The grading is over-emphasized and the learning functions under-emphasized. There is a tendency to use a normative rather than criterion approach, which emphases competition between pupils rather than personal improvement (Molwane, [12]).

\section{D\&T Teachers and Levels of Blooms Cognitive Skills}

With regard to the mental rigor involved in developing lesson plans that incorporate higherorder thinking, there are two additional challenges that a teacher takes on (Brandt, [13]). The first is motivation. It almost goes without saying that students are more likely to engage in higher-order, critical thinking when they are motivated to do so. Creative teachers capitalize on this connection and therefore (a) use real-world problems that are of genuine concern to students to foster their critical thinking skills, and (b) engage students with compelling challenges to their pre-existing biases, drawing them into analytical debates about difficult issues. Second, to truly encourage higher order thinking, a teacher must design assessments and exercises that actually use new and novel situations and problems. This is no small task. But, if at the core of our concept of higher-order thinking is students' ability to apply knowledge to new situations, teachers have to be constantly creating opportunities for that sort of transferable of knowledge. That means creating those new situations.

As one of the goals of the junior secondary school programme, D\&T is intended to stimulate cognitive, creativity and imagination in students as they solve real life problems in their communities. This idea is illustrated by Walsh (Walsh [14]). During 1998, Walsh a design and technology teacher, made an experiment on how students could be taught evaluation skills in the process of designing an artifact at Gorokan High School in New South Wales Australia., She participated in the Curriculum Support Directorate's Literacy Action Research Project and undertook to focus on how literacy strategies could be used to improve the evaluation skills of her students. Students were assigned the designing of artifacts as a group task where they were to come up with a list of questions which should be asked such as what size, color or the type of material to be used. In asking and answering these questions students had to use judgments. Students consulted and discussed ideas with each other in what can be described as peer evaluation. 
One of the most efficient and effective evaluation approaches for students to use is talking and listening. Talking through thinking processes with their peers or their teacher helps students to enlist the help of other people and to make more considered decisions. Student discussion and peer evaluation are effective strategies and can achieve valuable outcomes where students have been taught and have practiced group work and collaboration skills. They need to demonstrate respect, tact and objectivity in their interactions. Students also need to have a clear understanding of what they are being asked to do, and checklists, which ensure thoroughness and can, help to keep students focused. Brainstorming, PMI (Plusses, Minuses and Interesting things) charts and mind-mapping can be used by students as an evaluation strategy. A group secretary can be appointed to help record students' comments for later reflection and action. In some situations it may be more effective for students to evaluate another student's work using drawings or written responses, rather than oral responses.

The subject in addition enables students to apply scientific and technological knowledge and principles, knowledge from other subjects and other relevant sources, in problem solving activities related to their communities. It provides students with broader design and technology concepts and principles that allow them to expand their thinking capacity to tackle practical real life problems in their communities (Molwane \& Mwendapole, [15]).

Students of D\&T can only attain these skills from a style of teaching which is designed to provoke higher order cognitive thinking. The study is indicating that D\&T intent to stimulate creativity. Students can only achieve or attain those creative thinking skills if they were being exposed to them (Norman [16]). The polymer acoustic guitar is an example of a technological innovation that demonstrates the need for design and technology curricular based on 'learning by doing' and 'teaching by showing'. Some knowledge, skills and values can be captured and expressed through natural language. However, others may be impossible to describe in this way. The necessary technology for design must be represented mathematically, then it must be learnt first in order to facilitate cognitive modeling.

To Wilson and Harris [17], cognitive development cannot be separated from design and technology. They have shown clear evidence that the different teaching methods and the range of pupil activities within D\&T assignments provide opportunities for cognitive development. The knowledge of D\&T was learned through social interactions. Pupils' capabilities were enhanced through their direct active socio-cultural interactions within a range of classroom settings involving different teaching methods. D\&T aids communication, and improves numeracy, information technology, working with others, improving performance, problem solving, and creativity.

A research study was carried out by Bungum et al., [18] in some Norwegian schools on whether Science and mathematics were consciously being applied during the design of projects and artifacts. The researchers videotaped lessons where students were working on projects. The videos were later analyzed and from which it was concluded that students and teachers found it difficult to apply mathematics and science knowledge in a formal sense to the design technology. What was also observed is that both students and teachers were more interested in the practical aspect of the subject. This research study recommended that the Design and Technology subject should not exist for the purpose of creating a context where knowledge from other subjects such as Science and Mathematics can be applied but should have its own epistemology. This was a rather controversial recommendation.

To Musta'amal, Norman, Jabor and Buntat [19] Computer Aided Design (CAD) enables designers to graphically model their ideas on the screen as a complete design proposal. This 
technology improved the quality of student output in the form of visual images and product realization. CAD is widely used in the design and engineering areas especially in product design and manufacturing. CAD has been utilized in many ways including draft, design, simulation, analysis and manufacturing. It plays great role in designing including styling, conceptual design, simulation, product, and detailed design. The increased use of digital media such as CAD to facilitate design activity has led to the need to consider what the impact it has on designers' performance. This study attempted to provide empirical evidence on the potential links between CAD and creativity when designing. Protocol analysis could be used to justify the use of verbal reports as data, especially as data regarding thinking. Computer aided design (CAD) is a vital resource for both teaching and assessing in design and technology.

\section{SUMMARY OF REVIEWED LITERATURE}

Design and technology is a special subject which has various entities. Therefore, it needs special treatment in both teaching or pedagogy and assessment. The researcher has gained a lot of information about the learning resources. They positively affect both teaching and assessment of design and technology when used properly. For instance, the use of computers in teaching is very vital to the teaching of this subject. School-based assessment on the other hand is also very vital to assessment of the students' learning. Lastly, the literature review has yielded a lot of information that will inform the study. According to the literature review what design and technology teachers are doing is completely different from what they should be doing in teaching and assessing in D\&T. Teachers are not giving the students an opportunity to search information for themselves. Some of the studies have identified problems of technology integration and therefore the researcher will take note of this when carrying out the research. Students' assessment is predominantly on the multiple choice items and they do not gauge the students on design tasks.

\section{Research Paradigm and Method}

\section{RESEARCH METHODOLOGY AND DESIGN}

The methodology of this study was informed by post-positivist philosophy which underlies quantitative research approach. The study utilized the quantitative approach because it meets most of the criteria required by the approach. Ary, Jacobs and Sorensen [20, p. 645] described quantitative approach as "research method that uses objective measurement to gather numeric data that are used to answer questions or test predetermined hypotheses. It generally requires a well-controlled setting". The study explored factors that impede or hinder design and technology teachers in teaching and assessing higher-order cognitive skills in design and technology at Botswana junior secondary school levels in South East region. Therefore, the use of this quantitative approach in this research was very significant to provide the researcher with a variety of tools from the statistics and operational research. In addition, quantitative results or outcomes would be helpful for resources and expected future trends.

\section{Population, Sampling and the Sample for the study}

The target population for this study was design and technology teachers in Botswana junior secondary schools in South East region. These were chosen because they teach and are subject specialists who assess the learning in design and technology. Furthermore they know the real factors affecting their daily work especially in both teaching and assessment. The study intends to establish whether D\&T teachers teach and assess higher-order cognitive skills in design and technology. This region has twenty one (21) junior secondary schools and three (3) clusters. The traveling covered the following: Gaborone city, Ramotswa, Tlokweng, Otse and Mogobane villages. The researcher preferred to use design and technology teachers because they have got knowledge about teaching and assessment of this subject. Non design and technology teachers 
were not used in the study because they cannot give rich information about teaching and assessment of design and technology. The South East region has 21 junior secondary schools and design and technology has 60 teachers.

The study utilized purposive sampling where design and technology teachers of Botswana junior secondary schools in South East region were being selected. A purposive sampling is a rich case sample where a researcher chooses a few individuals whom he/she considers to be knowledgeable about the issue under study (Mertens [21], p. 261) Purposive sampling depends on the researcher to choose these individuals, and this raises the question on how does one choose some individuals and exclude others. If used properly, purposive sampling can be a powerful tool in research to obtain an in-depth knowledge related to the problem under study.

There were 45 teachers selected from 16 junior secondary schools in this region of south east. The region has three (3) clusters, which are Gaborone West cluster, Gaborone East cluster and South East cluster. Fifteen (15) teachers were selected from each cluster as participants in the study.

\section{Instrumentation}

The instrument used in this research was a questionnaire with closed-ended items. This was designed to collect data from the selected D\&T teachers. Items that are closed ended are conclusive in nature as they were develop to measure each of the research variables and designed to generate concrete data that is quantifiable for computer data analysis. Nunan [22] says that questionnaire, is very cost effective when compared with other methods namely interview, telephone or face to face surveys and observation. The questionnaire was selected to be used in this study to reduce or decrease bias whereby the respondents will not be influenced by the researcher's own opinion in answering questions in a certain behavior. This is because there are no verbal or visual clues to influence the respondents.

\section{Data collection}

Data were collected from design and technology teachers of Botswana junior secondary schools in South East region using questionnaire. The questionnaire was administered in two (2) phases. Phase 1 the questionnaire was administered to five (5) teachers and the intention was to check whether they will give expected results or not. Questionnaire was administered to forty five (45) teachers of design and technology in sixteen (16) junior secondary schools of South East Region. The researcher distributed the questionnaire and the relevant authorities were being consulted in their respective schools. The permission letter from the Ministry of Education and Skills Development was being given to all participating schools. However, teachers were not forced to participate. The questionnaire was being administered by the researcher to design and technology teachers. Teachers were given were given one to two weeks to answer the questions. According to the order stated in permission letter, the researcher was not allowed to collect data during lesson times. All considerations were put in place to ensure ethical validity for the study.

\section{Data Preparation, Operational Definition of Variables}

Coding and adding up scores on each of the items designed to measure each variable. Were done to operationally define the research variables. Hence variables as concepts were replaced by numbers so that the computer program is able to read and analyze data. All collected data was quantified to be readable by computer. For instance, for each item in the questionnaire a response was replaced by a strongly agree $(S A)=4$, agree $(A)=3$, disagree $(D)=2$ and strongly disagree $(S D)=1$. For demographic variables male $=2$, female $=1$, qualification such as diploma 
$=1$, bachelor of degree $=2$. Each hypothesis was stated and tested in the statistical null form and the variables involved were identified by type and nature.

\section{ANALYSIS OF DATA AND INTERPRETATION OF RESULTS \\ General Description of Data}

The level to which design and technology teachers in Botswana junior secondary schools in South East Region teach to develop six (6) levels of Blooms' cognitive skills.

The level to which design and technology teachers in Botswana junior secondary schools in South East region assess to develop six (6) levels of Blooms' cognitive skills.

All the hypothesis of the study will be stated and their data presentations in form of tables. Each hypothesis is tested as indicated on Table 6 and at .05 alpha levels.

\section{Hypothesis I}

Design and technology teachers in Botswana junior secondary schools in South East region do not teach to develop skills at each level of Bloom's taxonomy to a significant level.

The results from Table 2 showed that there is difference in the way teachers teach to develop the levels of Blooms' cognitive skills in design and technology (D\&T) of Botswana junior secondary schools in South East region, for instance (memory, $\overline{\mathrm{X}}=13.405, \mathrm{SD}=1.654$; comprehension, $\overline{\mathrm{X}}=12.667, \mathrm{SD}=1.817$; application, $\overline{\mathrm{X}}=11.996, \mathrm{SD}=2.683$; analysis, $\overline{\mathrm{X}}=$ $12.571, \mathrm{SD}=2.461$; synthesis, $\overline{\mathrm{X}}=12.095, \mathrm{SD}=2.945$ as well as evaluation, $\overline{\mathrm{X}}=11.357, \mathrm{SD}=$ 2.970 , df $=41$ ). The population mean was 1.98. The difference between the means is statistically significant at .05 alpha level (memory, $t=13.343, \mathrm{df}=41$; 
Table 2

Level to which D\&T Teachers Taught Levels of Blooms' Cognitive Skills: $(u=10.00)$

\begin{tabular}{|c|c|c|c|c|c|c|c|}
\hline \multirow{2}{*}{ Variable } & \multirow{2}{*}{$\overline{\mathbf{x}}$} & \multirow{2}{*}{ SD } & \multirow{2}{*}{ SE } & \multicolumn{2}{|c|}{$\overline{\mathbf{x}}-\boldsymbol{\mu}$} & \multirow{2}{*}{$\mathbf{t}$} & \multirow{2}{*}{$\mathbf{p}<$} \\
\hline & & & & Diff. & SED & & \\
\hline Level to which memory skill is taught & 13.405 & 1.654 & .255 & 3.405 & 0.255 & 13.343 & .000 \\
\hline $\begin{array}{l}\text { Level to which comprehension skill is } \\
\text { taught }\end{array}$ & 12.667 & 1.817 & .280 & 2.667 & 0.280 & 9.512 & .000 \\
\hline Level to which application skill is taught & 11.976 & 2.683 & .414 & 1.976 & 0.414 & 4.775 & .000 \\
\hline Level to which analysis skill is taught & 12.571 & 2.461 & .380 & 2.571 & 0.380 & 6.772 & .000 \\
\hline Level to which synthesis skill is taught & 12.095 & 2.945 & .454 & 2.095 & 0.454 & 4.611 & .000 \\
\hline Level to which evaluation skill is taught & 11.357 & 2.970 & .458 & 1.357 & 0.458 & 2.961 & .005 \\
\hline
\end{tabular}

$\mathrm{df}=41$ comprehension, $\mathrm{t}=9.512, \mathrm{df}=41$; application, $\mathrm{t}=4.775, \mathrm{df}=41$; analysis, $\mathrm{t}=6.772, \mathrm{df}=$ 41; synthesis, $\mathrm{t}=4.611, \mathrm{df}=41$ and evaluation $\mathrm{t}=2.961, \mathrm{df}=41$ ). The null hypothesis was rejected $(\mathrm{p}<.05)$. This means that D\&T teachers teach to develop Blooms' cognitive skills at significant level.

\section{Hypothesis II}

Design and technology teachers in Botswana junior secondary schools in South East region do not assess to develop skills at each level of Bloom's taxonomy to a significant level.

The results in Table 3 showed that there is a difference in which teachers assess various levels of Blooms' cognitive skills in design and technology (D\&T) at memory $(\overline{\mathrm{X}}=12.024, \mathrm{SD}=1.814$ ), comprehension $(\overline{\mathrm{X}}=11.191, \mathrm{SD}=1.627)$ application $(\overline{\mathrm{X}}=10.381, \mathrm{SD}=1.847)$, analysis $(\overline{\mathrm{X}}=$ $10.357, \mathrm{SD}=1973)$, synthesis $(\overline{\mathrm{X}}=10.786, \mathrm{SD}=2.590)$ and evaluation $(\overline{\mathrm{X}}=11.357, \mathrm{SD}=2.229)$. The population mean was 1.98. The difference between the means is not 


\section{Table 8}

Level to which D\&T Teachers Assess Blooms' Cognitive Skills (u=10.00)

\begin{tabular}{|c|c|c|c|c|c|c|c|}
\hline \multirow{2}{*}{ Variable } & \multirow{2}{*}{$\overline{\mathbf{x}}$} & \multirow{2}{*}{ SD } & \multirow{2}{*}{ SE } & \multicolumn{2}{|c|}{$\overline{\mathbf{x}}-\boldsymbol{\mu}$} & \multirow{2}{*}{$\mathbf{t}$} & \multirow{2}{*}{$\mathbf{p}<$} \\
\hline & & & & Diff. & SED & & \\
\hline Level to which memory skill is assessed & 12.024 & 1.814 & .280 & 2.024 & 0.280 & 7.229 & .000 \\
\hline $\begin{array}{l}\text { Level to which comprehension skill is } \\
\text { assessed }\end{array}$ & 11.191 & 1.627 & .251 & 1.190 & 0.251 & 4.743 & .000 \\
\hline $\begin{array}{l}\text { Level to which application skill is } \\
\text { assessed }\end{array}$ & 10.381 & 1.847 & .285 & .381 & 0.285 & 1.337 & .189 \\
\hline Level to which analysis skill is assess & 10.357 & 1.973 & .304 & .357 & 0.304 & 1.173 & .248 \\
\hline $\begin{array}{l}\text { Level to which synthesis skill is } \\
\text { assessed }\end{array}$ & 10.786 & 2.590 & .400 & .786 & 0.400 & 1.966 & .056 \\
\hline $\begin{array}{l}\text { Level to which evaluation skill is } \\
\text { assessed }\end{array}$ & 11.357 & 2.229 & .344 & 1.357 & 0.344 & 3.946 & .000 \\
\hline
\end{tabular}

$\mathrm{df}=41$ statistically significant at some levels which are (application, $\mathrm{t}=1.337, \mathrm{df}=41$; analysis, $\mathrm{t}=1.173, \mathrm{df}=41$ and synthesis, $\mathrm{t}=1.966, \mathrm{df}=41)$. The null hypothesis was retained $(\mathrm{p}>.05)$. Nevertheless, the difference among the means for assessment of Blooms' cognitive skills was statistically significant at .05 level memory $(t=7.22, \mathrm{df}=41)$, comprehension $(\mathrm{t}=4.743, \mathrm{df}=$ 41 ) and evaluation $(t=3.946, d f=41)$. The null hypothesis was rejected $(p<.05)$.

\section{SUMMARY OF THE FINDINGS}

The purpose of the study was to find out the extent to which design and technology teachers of Botswana junior certificate in south east region teach for the development of an assessment of Bloom's higher order cognitive skills in their respective subjects. The research was motivated by declining students' performance in D\&T. The research was based on six (6) levels of Bloom's taxonomy of cognitive skills and design thinking theory as its conceptual framework. The study employed a quantitative research methodology informed by post positivist paradigm. The post positivist philosophy is flexible in its application of the scientific method. The instrument of data collection was questionnaire with 56 items. The target population was D\&T teachers of South East region and 42 teachers were chosen by using purposive random sampling from 16 junior secondary schools which participated in the study. Data was analyzed using computer package called Statistical Packages for Social Sciences (SPSS). Although purposive random sampling was done to increase credibility of the results it did introduce an element of subjectivity together with the self-reporting by respondents of the questionnaire.

The study has found that teachers taught and assessed higher order cognitive skills in D\&T rather differently from low order skills like Memory. It was also found that the assessment component of the following skills Analysis, Synthesis and Application was not done as well as the teaching component on the same skills.

\section{DISCUSSIONS}

The overall purpose of the study was to determine the extent to which design and technology (D\&T) teachers teach for the development and assess higher-order cognitive skills in South East Region Botswana junior secondary schools. The discussion will take into account professional knowledge, the empirical findings of related studies and the related theory. The 
findings will be integrated in relation to each hypothesis. This discussion considers teaching and assessing of design and technology separately.

\section{Teaching and Assessment of Higher-order Cognitive Skills Teaching}

The findings from the testing the first hypothesis on teaching have shown that design and technology teachers of South East region in Botswana junior secondary schools are doing excellent work on teaching to develop the memory skill of Blooms cognitive domain. They also teach to develop this level of memory (remembering) by teaching D\&T students on how to choose the correct or appropriate materials during both designing and manufacturing. Students choose the materials based on the properties they were taught in class. They also teach D\&T students on how to define and describe jargons (terms) of the subject, for example, the students of this subject must be able to define and describe how the tools are used and machines work. They also teach learners to label and list the parts of both tools and machines of design and technology. They also teach the students how to identify and name the tools of this subject.

On their teaching to develop the comprehension (understanding) skill, the results from the teachers confirmed that D\&T teachers are proceeding very well on this level. However, their performance is less than the one on the memory level. They teach their students to categorize (classify) resistance of materials and structures in their respective classes. They also teach their students to demonstrate the ability of using various materials, finishing and assembling techniques on metals, wood and plastics. They also teach their learners to communicate through graphic communication. For instance, D\&T students are taught to express themselves through illustration techniques. They also teach their students to compare materials when designing and after comparing the students are able to decide the right or appropriate materials to be used in their respective design. D\&T teachers also teach the students how to construct the products by using various resistance materials of their choices. Resistance materials refer to wood work, plastic technology and metal work technology which are commonly used in design and technology.

On the application level, D\&T teachers are doing excellent work on teaching to develop this skill. However, they need to work harder on the application level skill because the findings showed a lower performance when compared to findings for memory and comprehension levels. They teach their students to implement (execute) by using design skills. They also teach their students to model products by using various design skills, for instance, students are taught manufacturing skills by making working models or prototypes to display how machines and electronics work. D\&T teachers are exposing their students to solve the problems within their environment. For example, the students can be taught to repair broken furniture in their schools. However, the researcher's observation is that all the junior secondary schools have broken furniture which is not repaired by the students but by craft improvers, hence denying students an opportunity to practice their application skills.

On the teaching to develop the analysis skill, the results from the teachers showed that their performance was better than the one on the application level. On the other hand, it was less than the performances attained on both memory and comprehension skills. Possibly design and technology teachers are doing well in this level because they teach their students how to analyze the concepts of design and technology as practical subject. They expose their students on the experiment skills. For instance, D\&T students can be taught on how to test (experiment) electronic circuits, the structures and strength of materials. They also teach the students to discriminate (distinguish) materials or any concepts of designs. They also teach their students 
to integrate (mix) materials when building or creating a product. For example, the students can be taught to mix both metals and wood when building or creating a product. They also teach the students to analyze (inspect) the existing products by giving both the strengths and the weaknesses of that particular product. They also teach the students to analyze the structural part of the product. They also teach students to make investigations on the products and teach to develop analytical skills on how to connect components to make one part.

On the teaching to develop the synthesis skill, the results from the teachers illustrated that D\&T teachers are doing moderately well on this level. Their performance is almost the same as the one on the application level but their teaching performance on the application part is little bit better than the one on the synthesis. D\&T teachers are doing a reasonably good job on the teaching of the synthesis skill, perhaps because they teach their students to construct, compose, create and design products of their choices. They do not restrict their learners on constructing products. They also elaborate on their teaching. Lefrancois [23] described elaboration as a cognitive process whereby information is extended or added to make it more memorable. They teach to develop D\&T students to invent and modify their designs.

The last level of teaching is evaluation and under this level design and technology teachers are teaching to develop the evaluation skill of the students to a significant level. However, their performance at the evaluation level was not achieved to the same extent as on the other levels of Blooms' cognitive domain. They also prioritize their teaching in terms of what should be taught. They also teach to develop their students on how to recommend good design by giving some justifications. Masek and Yamins [10] found that through evaluation some weaknesses and strengths of teaching D\&T can be spotted and that critical thinking is about teaching students to correctly use concepts, principles and measures.

\section{Assessment}

The findings from the first hypothesis on the assessment have shown that design and technology teachers of South East region in Botswana junior secondary schools are doing a good job only on three levels of Bloom cognitive domain but on the other three levels of the same domain have not been achieved to the same extent based on the quantitative results. Surprisingly, design and technology teachers are not assessing the level of application to a significant level whereas the findings of the teaching on the same level have shown that they are doing well. Probably they are not assessing the application skill to a significant level because they do not assess their students to apply what they have learnt. For example, the students can be assessed to apply their skills to solve problems within their community. They do not assess their students on modeling techniques to exhibit their expertise. D\&T teachers predominantly assess the students on the multiple choice items and ignore practical assessment where the students could demonstrate application skills by trying to solve the problems within their community. They do not judge the students on their ability to execute the illustration techniques. Therefore, D\&T teachers are not using assessment to inform their teaching approaches. This is supported by Molwane [12] who found that the current school based assessment of D\&T encourages competition among the students rather than development.

Teachers are not doing well on the analysis level because they do not assess the students' analysis of products. For instance, the students can be assessed to analyze a product by looking at the function, structure and aesthetics. They do not assess the students on comparison of properties of materials when designing a product. The students are not assessed to analyze a task through the use of diagrams. For example, students can be assessed to analyze an artifact 
through the use diagrams. The students' ability on analysis is not tested on the integration of resistance materials where students are mixing two or three materials.

D\&T teachers are not assessing the synthesis skill of Blooms' cognitive domain to a significant level. The findings are the same as those found on both the application and analysis skills. The results indicate that the D\&T teachers are doing well in teaching but poorly on assessment. The assessment does not judge the students on how to generate compose and modify what they have created. The assessment is too shallow to develop the thinking skills of the students. The students are not given the opportunity to elaborate what they have designed and to modify the existing products in order to improve them. The students are not assessed on their innovative skills which they can use to solve the real life problems.

Amazingly, the findings on the evaluation level have shown that teachers assess this skill to a significant level; the results are similar to those found on the teaching of the same skill. May be the teachers are doing well on this level because they assess the students to justify decisions taken on their respective projects. They also assess the students on their ability to convince and defend their ideas. They assess the students on how to critique the ideas during concepts selection. For instance, the students are expected to justify by giving reasons for their choice. They also assess the students on how to rank and recommend the skills. In the final stage of design process the students are assessed to detect both weaknesses and the strengths of the product. Finally, teachers are not using the assessment to inform their teaching and they conduct both teaching assessment as two unrelated activities.

\section{RECOMMENDATIONS}

- The Department of curriculum development and evaluation should reduce the subject taken by the students at junior secondary schools because they are nine and this is compromising the scope of subject to be attained by the students.

- Design and technology is assessed through three papers but Paper 1 is composed of multiple-choice items, therefore, it has to be phased out because higher order cognitive skills are impossible to be assessed in this paper.

- The school managers must be encouraged not to violate the number of students to be admitted into design and technology.

- The Ministry of Education through relevant department will avail the resources to schools in order to reduce buriers existing in teaching and assessment of higher order cognitive skills in D\&T.

\section{Further Study}

The researcher recommends applying mixed method for further studies to find solutions to this problem. The qualitative part will compliment quantitative and lead to more comprehensive findings. Even methodological triangulation will be useful in further studies to find solution to this problem. Further studies could also be done find out how design and technology teachers could be more engaged in Blooms' cognitive skills.

\section{References}

Kerka, S. (1992). Higher order thinking skills in vocational education. ERIC Digest No. 127. Retrieved from: http://eric.ed.gov/?id=ED350487

Kewagamang, M. (2013, August 08). Design and technology costly. Botswana daily news. Retrieved from http://www.dailynews.gov.bw

Molwane, O. (2013, August 8). Design and technology costly. Botswana Daily News; Retrieved from http://www.dailynews.gov.bw

Venson-Moitoi, P. (2012, November 09). India donates ICT equipment. Botswana Daily News, p. 3 
Ngakaemang, K. M., \& Nenty, H. J. (2017). Teaching and Assessing High-order Skills by Design and Technology Teachers in Botswana. Advances in Social Sciences Research Journal, 4(5) 13-28

Botswana Examination Council (2009) Assessment procedures, design and technology: Gaborone. BEC

Bloom B. S. (1956). Taxonomy of educational objectives, Handbook I: The cognitive domain. New York: David McKay Co Inc.

Nenty, H.J. (1985). Fundamentals of educational measurement and evaluation. Unpublished manuscript. University of Calabar, Nigeria.

Gagne, R. M., Briggs, L. J., \& Wager, W. W. (1992). Principles of instructional design. Fort Worth: Harcourt Brace Jovanovich.

Scott-Webber, L., \& Corcorran, S. (2013). Design thinking: Theory \& practice. New York: Wadsworth Cengage Learning.

Masek, A., \& Yamin, S. (2011). The effect of problem based learning on critical thinking ability: A theoretical and empirical review. International Review of Social Sciences and Humanities, 2, 215-221.

Moalosi, W. T. S. (2012). Teacher efficacy: Is student engagement essential in Botswana junior secondary schools? International Journal of Scientific Research in Education, 5 (3), 207-213. Retrieved from http://www.ijsre.com

Molwane, O.B. (2000). Assessing technology education in Botswana junior secondary curriculum: Case study of teachers' classroom practices. In R. Kimbell (Ed.), Design and technology. International Millennium Conference. Wellesbourne: The D\&T Association, pp. 121-127

Brandt, R. (1993). On teaching for understanding. Educational Leadership, 1(3), 10-3.

Walsh, F. (1998). Strengthening family resilience. New York: Guildford Press.

Molwane, O., \& Mwendapole, C. (2008). Design and technology education and the concept of intellectual property. Open Journal Systems, 13 (2) 163-179.

Norman, E. W. (2000). The teaching and learning of technology for design . Design and Technology International Millennium Conference (pp. 128-135). Wellesbourne: D\&T Association.

Wilson, V., \& Harris, M. (2004). A review of the impact of design and technology in schools in England. Journal of Technology Education, 15 (2), 46-65.

Bungum, et al. (2014). Insights from research in science teaching and learning: selected papers. Retrieved from: https://books.google.co.bw/books?isbn=3319200747

Musta'amal, A., Norman, E., Jabor, M, K., \& Buntat, Y. (2012). Does CAD really encourage creative behaviours amongst Its. RHED2012, 34-40.

Ary, D., Jacobs, L. C., \& Sorensen, C. (2010). Introductin to research in education. New York: Wadsworth Cengage Learning.

Mertens, D. M. (1997).Research methods in education and psychology: Integrating diversity with quantitative and qualitative approaches. London: Sage Publications.

Nunan, D. (1993). Introducing discourse analysis. London: Penguin

Lefrancois, G. R (1997) Psychology for teaching. New York: Wadsworth. 